\title{
Update on the management of symptoms in schizophrenia: focus on amisulpride
}

This article was published in the following Dove Press journal:

Neuropsychiatric Disease and Treatment

15 May 2009

Number of times this article has been viewed

\section{Ann M Mortimer \\ Department of Psychiatry, Hertford Building, The University of Hull, Cottingham Road, Hull HU6 7RX, United Kingdom}

Correspondence: Ann M Mortimer Department of Psychiatry, Hertford Building, The University of Hull, Cottingham Road, Hull HU6 7RX, United Kingdom

Tel +44 I 482464565

Fax +44 I 482464569

Email a.m.mortimer@hull.ac.uk

\begin{abstract}
Amisulpride is an atypical antipsychotic drug with a unique receptor pharmacology which is dose dependent. It is a standard treatment in dysthymia as well as in psychosis. Amisulpride is efficacious, effective and well tolerated in positive symptoms of schizophrenia: there is extensive evidence that it treats negative symptoms when given in low doses, although relative lack of EPS and an antidepressant effect may contribute. In first-episode patients amisulpride is an option, although there is little comparative work available. Amisulpride has the best evidence as an effective adjunct to clozapine treatment. Regarding intellectual function, amisulpride appears cognitive sparing but the clinical relevance of this remains obscure. There is evidence that amisulpride can improve social function but again there is little comparative work to demonstrate any particular advantages. Regarding the current conventional versus atypical antipsychotic controversy, amisulpride did better in switching studies and meta-analyses than in the single large pragmatic randomized trial reported to date. It is a versatile drug, and may offer advantages over other atypical antipsychotic drugs in the treatment of negative and depressive symptoms, and tolerability advantages such as the avoidance of weight gain. Essentially it rests with the treating clinician to employ a rational psychopharmacological approach towards the individual patient: there will be few circumstances in which amisulpride will not be a likely contender as a treatment choice.
\end{abstract}

Keywords: amisulpride, negative symptoms, clozapine, depression

\section{Introduction}

Amisulpride is an atypical antipsychotic drug: it is one of the class of atypical antipsychotic drugs indicated for the treatment of schizophrenia. Amisulpride is a benzamide drug, with both antipsychotic and antidepressant properties. It is very similar to sulpiride, which was introduced previously: amisulpride has been much more extensively marketed than sulpiride in recent years.

Amisulpride was first licensed in France in 1986, but was not available in the UK until 1998. It is not licensed in the US. Given the introduction of several other atypical antipsychotic drugs over the last 10 years, and the ongoing controversy about their efficacy and tolerability compared to conventional antipsychotic drugs, a review of amisulpride seems timely. This review concentrates on symptomatic efficacy in schizophrenia across syndromal domains.

\section{Neuroscience and pharmacology}

The affinity profile of amisulpride (and sulpiride) is unique amongst both conventional and atypical antipsychotic drugs. In vitro, amisulpride selectively binds to D2 and 
D3 dopamine receptors, but with preference for the latter. Unlike the other drugs in the atypical antipsychotic class, amisulpride is devoid of any affinity for serotonergic, alphaadrenergic, histaminergic or muscarinic receptors. Another difference between amisulpride and alternative atypical antipsychotic drugs is that it binds to surface receptors only, not intracytoplasmic receptors as well. ${ }^{1}$ The clinical relevance of this is not entirely clear.

The reformulated dopamine hypothesis of schizophrenia has postulated that overactivity of dopaminergic neurones in limbic areas of the brain is responsible for positive symptoms, while dopaminergic under-activity in the frontal cortex results in negative symptoms and cognitive impairment. ${ }^{2}$ While D2 receptors are widely distributed through the brain, D3 receptors are concentrated in limbic and cortical areas, which have been repeatedly implicated in schizophrenia pathophysiology. This may give amisulpride advantages in that it is more closely targeted to the relevant neurotransmitter systems than alternative antipsychotic drugs. Moreover a relative lack of nigrostriatal binding could reduce the problem of extrapyramidal side effects. Furthermore, amisulpride has preferential affinity for presynaptic autoreceptors, as opposed to the affinity for postsynaptic receptors which predominates the action of other antipsychotic drugs. In rats, low doses of amisulpride preferentially increase dopaminergic transmission in the mesolimbic system. ${ }^{3}$

It was therefore predicted that amisulpride would alleviate both the proposed dopaminergic underactivity in the frontal cortex, and the overactivity in the limbic system, which characterize schizophrenia pathophysiology, without the inevitable induction of extrapyramidal side effects.

This unique pharmacology is largely consistent with the therapeutic profile of amisulpride: it has been shown to control both positive and negative symptoms of schizophrenia, and is reasonably well tolerated by virtue of its lack of other significant affinities. For instance amisulpride has a low propensity to cause catalepsy in rats, ${ }^{4}$ and a low incidence of extrapyramidal side effects in clinical studies. However, failure to induce catalepsy may be species specific. ${ }^{5}$

Even so, neuroimaging in humans has demonstrated reasonable separation between dosages associated with therapeutic as opposed to extrapyramidal side effects. ${ }^{6}$ Later work has reported two distinct binding profiles according to dose: striatal binding is only present at high dosage, at low dosage extrastriatal binding alone was observed ${ }^{7}$ validating reports of low dose efficacy for negative symptoms. However there are other reports to the effect that amisulpride and risperidone demonstrate very similar D2/D3 binding in limbic and striatal areas, in both patients and healthy volunteers. ${ }^{8}$ More work $^{9}$ confirmed that amisulpride does bind to D2 receptors and this is dose dependent.

On the other hand, amisulpride's unusual affinity for presynaptic dopaminergic autoreceptors may explain its efficacy for negative symptoms at low doses ${ }^{10}$ and is efficacy in dysthymia and in chronic mild depression. ${ }^{11}$ Moreover, the fast dissociation hypothesis may contribute to the explanation of the atypical clinical profile of amisulpride. ${ }^{12}$

Healthy volunteer studies suggest little pharmacokinetic differences between young and elderly subjects. ${ }^{13}$ In humans, a dose ranging study established the optimum dose of amisulpride in acute schizophrenic relapse as 400 to $800 \mathrm{mg} .{ }^{14}$ There was no increase in extrapyramidal side effects, apparently, between a low dose of $100 \mathrm{mg}$ daily and $1200 \mathrm{mg}$. However, amisulpride is prone to inducing neuroendocrine side effects such as hyperprolactinemia, perhaps to a greater degree than conventional antipsychotic drugs. ${ }^{15,16}$

Unusually, amisulpride is not extensively metabolized, but cleared by renal excretion ${ }^{17}$ This makes it potentially useful in patients with compromised hepatic function, but there is no research evidence to examine this issue.

Overall, amisulpride's pharmacodynamic and pharmacokinetic properties indicate potential usefulness in a variety of clinical scenarios.

\section{Amisulpride for positive symptoms}

It is well established that amisulpride is at least as effective in the control of positive symptoms as conventional antipsychotic drugs. ${ }^{18}$ Indeed were this not the case, amisulpride would not have been authorized for the market. Moreover, amisulpride is at least as effective for the control of positive symptoms as some other atypical drugs, ${ }^{19,20}$ but is less likely to induce extrapyramidal side effects. ${ }^{21}$ For instance one study ${ }^{22}$ examined whether D1 receptor antagonism was necessary to treat positive symptoms, using a double blind randomized comparison of amisulpride with flupenthixol. Amisulpride was as least as effective, and better tolerated. This has been demonstrated repeatedly in patients in acute relapse. $^{23}$

There are suggestions that amisulpride acts more rapidly than other drugs in acute relapse, when a predominance of positive symptoms would be expected. ${ }^{24}$ Indeed, it has more recently been shown in a large study of pooled data that there is more overall and positive symptom improvement in the first 2 weeks of treatment with amisulpride than in the second 
2 weeks, moreover, $68 \%$ of the improvement took place in the first 4 weeks of treatment. ${ }^{25}$ There is a similar finding in a small study of delusional disorder: amisulpride was effective within 2 weeks, continued to be effective at 3 months, and was well tolerated. ${ }^{26}$

Most of the evidence, then, regarding amisulpride in positive symptomatology points in the same direction, that amisulpride is efficacious and effective.

\section{Amisulpride for negative symptoms}

The negative syndrome implies an inability to respond to stimuli, whether these are internally or externally generated. Thus there is a lack, a 'poverty,' of normal mental activity and its consequences. This is most noticeable in ideation (thought) and emotional response (affect). It seems likely that the other hallmarks of the negative syndrome, such as poor social function, are secondary to these basic deficits. Unfortunately the term 'secondary negative symptoms' has been used to describe similar but unrelated presentations such as depression, Parkinsonism and 'neuroleptic induced dysphoria,' which may mimic the negative syndrome to the untrained observer (see Table 1). It is therefore very important in any study of negative symptoms to establish that what is being rated is genuinely negative symptoms, rather than the alternatives.

Amisulpride displays some beneficial effects in animal models of negative symptoms. ${ }^{27}$ These include increasing regional glucose utilization, a proxy for neuronal activity, in the rat equivalent of human brain areas involved in cognition, motivation and emotion. ${ }^{28}$

In the clinical arena, amisulpride in low doses $(100 \mathrm{mg}$ per day) was compared with placebo, double blind, in a large randomized trial ${ }^{29}$ which met criteria for valid evaluation. ${ }^{30}$ Patients had high levels of negative symptoms, and a DSM-III-R diagnosis of residual schizophrenia. There were substantial decreases in negative symptoms, about a third, in the amisulpride group: EPS were at placebo level. Positive, depressive and general symptoms were also significantly reduced, but the absolute changes were far less in percentage terms. Dropout rates were $20 \%$ for active treatment and $40 \%$ for placebo. It is difficult to find serious fault with this study or its findings, except to say that an active (conventional) comparator, had it produced an efficacy equivalent to placebo, would have made arguments for switching 'deficit' patients to low-dose amisulpride very hard indeed to refute.

Other studies of similar patients, although methodologically not as strong, have reported comparable findings. ${ }^{31-33}$

Even in acute exacerbation, when positive symptoms may predominate, and at high doses, amisulpride reduced negative symptoms more than haloperidol. ${ }^{34}$ However the dose of haloperidol utilized was relatively high at $20 \mathrm{mg}$ per day in this study. This criticism could not be leveled at a similar study, which compared amisulpride in acute relapse with moderately high ( $8 \mathrm{mg}$ daily) doses of risperidone. ${ }^{35}$ Again, amisulpride was superior for negative symptoms. Nevertheless it is difficult to be sure that apparent negative symptoms were not secondary to positive symptoms, for instance leading to active social withdrawal easily interpreted as unresponsiveness.

An open but randomized study of 60 long stay chronic inpatients ${ }^{36}$ demonstrated only a trend toward better improvement in negative symptoms on amisulpride versus haloperidol over 1 year. Nonetheless, amisulpride was better tolerated in terms of the need for antimuscarinic medication. It is likely that these patients were quite treatment resistant and that there was very limited room for improvement on either medication. A similar, later study ${ }^{37}$ demonstrated a small but significant benefit in negative symptoms for amisulpride versus haloperidol in chronic or subchronic patients over 1 year.

A meta-analysis of 18 randomized controlled trials $(\mathrm{RCTs})^{38}$ concluded that the supposed superiority of amisulpride for negative symptoms was genuine. The authors

Table I Classification of negative symptoms

\begin{tabular}{lll}
\hline Symptom type & Cause & Result \\
\hline Primary & Pathophysiology of schizophrenia: failure to respond & Poverty of ideation; poverty of affect \\
& Consequences of primary symptoms & $\begin{array}{l}\text { Loss of motivation; poverty } \\
\text { of speech; poverty of behavior; } \\
\text { loss of self-care }\end{array}$ \\
Secondary negative & $\begin{array}{l}\text { Parkinsonism; unresolved positive symptoms; } \\
\text { depression; oversedation; institutional environment; } \\
\text { schizoid premorbid personality }\end{array}$ & $\begin{array}{l}\text { Any of the above, plus additional } \\
\text { symptoms specific to the cause } \\
\text { of secondary symptoms }\end{array}$ \\
\hline
\end{tabular}


commented that this cast doubts on the requirement for serotonin 5HT2A antagonism as a mechanism conferring atypicality, not only in terms of negative symptom relief, but also regarding any reduced incidence of extrapyramidal side effects.

One neuroimaging study observed that frontal blood flow alterations occurred as expected in negative syndrome patients treated with low dose amisulpride, but clinical improvement was greatest in the patients whose negative symptoms were deemed secondary as opposed to primary. ${ }^{39}$ Even so, a meta-analysis of four studies of patients with primary negative symptoms reported that there was an effect versus placebo on primary negative symptoms, although some improvements on placebo questioned the durability of primary negative symptoms over time. ${ }^{40}$ This is surprising since the clinical impression is that negative symptoms are usually stable and difficult to treat.

A recent trial of low dose amisulpride versus ziprasidone in patients with predominantly negative symptoms reported that the drugs were equivalent. ${ }^{41}$ A large randomized placebo controlled comparator trial versus olanzapine also found the two drugs to be equivalent: the authors commented that relief from extrapyramidal symptoms and positive symptoms was unlikely to be a valid explanation, but antidepressant effects may have contributed. ${ }^{42}$

Overall, then, there is good evidence for the efficacy of low dose amisulpride in negative symptomatology, even though there may be some contamination of the improvements in terms of relief from depression and extrapyramidal side effects.

\section{Amisulpride in depression}

It is well established that dopamine antagonism may be associated with low mood and depressive symptoms, eg. ${ }^{43}$ There are particular arguments for the relevance of dopaminergic deficit in dysthymia. ${ }^{44}$ Regarding amisulpride, however, at low doses it exerts affinity for dopaminergic autoreceptors, thereby increasing rather than reducing dopaminergic output. ${ }^{11}$ Low doses potentiate prohedonic responses in rat models ${ }^{27}$ and amisulpride is active in other animal models of depression. ${ }^{45}$

There is good evidence that amisulpride is effective in dysthymia or chronic mild depression in low doses, ${ }^{46-54}$ Indeed, amisulpride treatment in dysthymia is now so well established that it has been used as a reference drug in a comparator controlled trial. ${ }^{55}$

Low dose amisulpride may also be effective in major depression; ${ }^{56-58}$ and in partially responding patients with dysthymia or major depression, versus fluoxetine. ${ }^{59}$ There is no pharmacokinetic interaction with lithium. ${ }^{60}$

Regarding whether these promising actions translate into efficacy for depressive symptoms in schizophrenia, a very common clinical problem (which frequently responds poorly to antidepressants) there are some suggestions that they do. Effects include observed reductions in suicidal behavior, although controlled studies are lacking. ${ }^{61}$ Later work $^{62}$ examined three studies which addressed depressive symptoms in acute exacerbation of schizophrenia treated with amisulpride, risperidone or haloperidol. Amisulpride was significantly superior to the other two drugs: the effect was enhanced in more severely depressed patients, and improvements were seen from the second week of treatment. There is one double blind randomized 8 week comparison against olanzapine in schizophrenia patients with co-morbid depressive episode, which demonstrated equivalence: however, the doses of amisulpride utilized were not low. ${ }^{63}$ Furthermore, olanzapine was associated with significant unwanted effects on weight and metabolism.

Amisulpride was compared with continuation of risperidone in a recent randomized open study of depressed patients with schizophrenia: amisulpride proved superior compared to ongoing risperidone treatment for depressive symptoms, although the doses used, again, were not low. ${ }^{64}$

In summary, there seems little doubt that amisulpride is efficacious in a variety of depressive disorders: the evidence in depressive symptomatology integral to schizophrenia is less solid, but even so indicates that a trial of amisulpride can be recommended in those circumstances.

\section{Amisulpride in first episode schizophrenia}

Amisulpride compared to usual treatment reduced positive and negative symptoms and improved global function in a late prodromal or early psychotic group of patients. ${ }^{65}$ Amisulpride was the treatment of choice for late prodromal patients in a randomized German study: ${ }^{66}$ treatment markedly enhanced the benefits of psychosocial interventions. ${ }^{67}$ There is one small study of amisulpride in first episode patients which demonstrated that after 6 months the negative symptoms and quality of life of the patients had improved. ${ }^{68}$

The European First-Episode Schizophrenia Trial $\left(\right.$ EUFEST) ${ }^{69}$ randomized 500 first episode patients in 14 countries to haloperidol or atypical antipsychotic treatment: amisulpride, quetiapine, olanzapine or ziprasidone. Despite a high discontinuation rate with haloperidol, 
$72 \%$ after one year, compared to significantly lower discontinuation of the other drugs $(40 \%, 53 \%, 33 \%$ and $45 \%$ respectively) the authors concluded that atypical drugs were not superior. Greater discontinuation with haloperidol was attributed to poor prescriber expectations of haloperidol, and this conclusion was substantiated by finding no difference between treatments in PANSS scores, although simpler scales did differ. EUFEST has generated much controversy.

The relatively limited evidence for the use of amisulpride in first episode patients makes it difficult to draw firm conclusions about its relative usefulness compared to other atypical or even conventional antipsychotic drugs, some of which may be better tolerated for instance regarding hyperprolactinemia. First episode schizophrenia is a clinical scenario where medication must very much be tailored to the individual patient. Nevertheless amisulpride would certainly not be ruled out from the range of first or second antipsychotic choices.

\section{Amisulpride in treatment resistance}

There is one report of the utility of amisulpride monotherapy in treatment resistant schizophrenia. ${ }^{70}$

An early study ${ }^{71}$ suggested that amisulpride was a useful adjunct when clozapine side effects could not be tolerated: the addition of amisulpride enabled the dose of clozapine to be halved in one patient. This was followed by three small open studies with promising results in respect of relief of symptomatology and global improvement, ${ }^{72-74}$ and one double-blind placebo controlled study. ${ }^{75}$ It was demonstrated that clozapine raised plasma levels of amisulpride, but whether this contributed to the effectiveness of the combination is not known. ${ }^{76}$

Regarding other atypical antipsychotic drugs, there is preliminary evidence that the combination of olanzapine and amisulpride may be effective ${ }^{77}$ and that other non-clozapine atypical antipsychotic combinations including amisulpride may be of value. ${ }^{78}$ Another small study observed that amisulpride augmentation of several atypical drugs including clozapine was effective in most patients. ${ }^{79}$

A more recent review of a large number of studies ${ }^{80}$ concluded, again, that amisulpride was one of a number of atypical antipsychotic drugs which could augment the actions of clozapine in treatment resistant patients. It has since been reported in a small study that combining amisulpride with clozapine enabled the dose of clozapine to be reduced by $13 \%$, the combination was effective and there were no substantial tolerability issues. ${ }^{81}$ The value of the clozapine/amisulpride combination has continued to be replicated. ${ }^{82}$ One very small, double blind randomized placebo controlled study failed to find any symptomatic effect, but secondary, global efficacy measures and depressive symptoms improved. Nonetheless, amisulpride side effects were in evidence. ${ }^{83}$

A later randomized study compared quetiapine with amisulpride added to clozapine in partially responding patients over 8 weeks. Both drugs were associated with an improvement but the degree was superior on amisulpride. ${ }^{84}$ Finally, the addition of amisulpride to clozapine has a useful antihypersalivation effect; ${ }^{85,86}$

As a whole, there is more evidence for the utility of amisulpride as an adjunct to clozapine than for any other antipsychotic drug, or indeed for any other augmentation with other drug classes.

\section{Amisulpride and cognition}

Cognitive impairment is ubiquitous in schizophrenia: there has been much interest in antipsychotic drugs as potential cognitive enhancers or detractors over the years. Amisulpride did not enhance alcohol induced cognitive impairment in healthy volunteers ${ }^{87}$ neither did it enhance the effects of sleep deprivation. ${ }^{88}$ Compared to haloperidol, again in volunteers, amisulpride did not disrupt cognitive skill learning on motor and executive tasks, like haloperidol there was cognitive slowing but to a much more minor degree. ${ }^{89}$ Amisulpride in a single dose up to $200 \mathrm{mg}$ did not impair performance on a battery of cognitive tests in young males, neither did it affect the impairment induced by lorazepam when both were given. ${ }^{90}$ In a 5 -day trial of amisulpride versus a low dose of haloperidol, $4 \mathrm{mg}$ daily in healthy volunteers, amisulpride failed to disrupt cognition significantly at all until the last day at the $400 \mathrm{mg}$ dose: substantially greater effects of haloperidol were apparent throughout. ${ }^{91}$ In a small study of healthy elderly volunteers, amisulpride actually enhanced cognitive performance compared to placebo: again, haloperidol impaired performance. ${ }^{92}$

A review of 19 studies of amisulpride which included cognitive tests concluded that there were no effects up to $400 \mathrm{mg}$ daily and only mild effects at higher doses. ${ }^{93}$ The alerting effects at low doses as observed on EEG recordings were emphasized. However, amisulpride does abolish the enhancement of memory in the context of emotionally aversive or arousing stimuli. ${ }^{94}$ Furthermore, in inpatients with schizophrenia, although amisulpride like other atypical antipsychotic drugs induced less psychomotor slowing than conventional drugs (possibly attributable to milder 
extrapyramidal effects) it failed to distinguish itself from other atypical and conventional drugs in standard nonmotor neuropsychological tests. ${ }^{95}$ One small switching study observed improved memory performance on amisulpride in patients previously treated with risperidone. ${ }^{96}$

As opposed to compromise of cognition, there is the question of whether amisulpride in low doses acts as a cognitive enhancer in schizophrenic patients. One small neuro-imaging study of patients with the negative syndrome suggested that it did. ${ }^{69,83}$ Another long term study of cognition in patients taking atypical antipsychotic drugs reported that patients treated with those which antagonized 5HT2A receptors experienced compromise, while those taking drugs which did not (amisulpride and quetiapine) had enhanced aspects of memory and executive function. ${ }^{97}$ This was partly replicated ${ }^{98}$ in a comparison of amisulpride and olanzapine: patients' cognition improved on both drugs, thus detracting from the notion that 5HT2A antagonism was a necessary prerequisite for antipsychotic drug induced enhancement of cognition in schizophrenia. A more recent randomized 6-month trial of acute patients again demonstrated cognitive improvements on both olanzapine and amisulpride ${ }^{99}$ but there was a particular advantage for amisulpride in a verbal memory test.

It is difficult to make clinical sense of these studies overall. Essentially it is important to spare cognition when treating psychosis, and amisulpride does appear to pass this test. However, the functional or adaptive effects of small changes in neuropsychological task performance are unlikely to be of pronounced relevance to most patients.

\section{Amisulpride and adaptive function}

There is one study demonstrating sustained improvement on a measure of social function during amisulpride treatment. ${ }^{100}$ A double-blind 4-month RCT using haloperidol as a comparator found that amisulpride was associated with improved quality of life and functional status. ${ }^{101}$ Further work concurred that amisulpride is significantly more effective than haloperidol and placebo in a number of social function and quality of life measures. ${ }^{102}$ A naturalistic mirror image study over a year demonstrated improvements in global function, quality of life and service uptake, rendering amisulpride more cost-effective than previous treatment. ${ }^{103}$ Compared with antipsychotic drugs with strong serotonin 5HT2A affinity, patients treated with amisulpride improved their social function in the long term. ${ }^{104}$

A large study of subjective well-being ${ }^{105}$ reported that amisulpride treatment was effective in improving patients' well-being, but much of the response was attributable to the resolution of poorly controlled positive symptoms.

Essentially this work reiterates that the results of effective antipsychotic drug therapy go beyond simple symptom reduction and control, but extend to adaptive functionality: it is not clear whether amisulpride is superior to other antipsychotic drugs in this regard, with the possible exception of haloperidol.

\section{Discussion: differential indications for amisulpride?}

The first clear statement to appear in the literature, to the effect that the advantages of atypical antipsychotic drugs over the conventional variety did not imply differential indications (with the exception of clozapine for treatment resistance) appeared in $2000 .{ }^{106}$ This was rapidly followed by a meta-analysis which argued that any advantages of atypical antipsychotic drugs, including amisulpride, were attributable to excessive doses of the conventional comparator, particularly when it was haloperidol. The authors recommended that atypical drugs should not be used unless the patient was intolerant of the side effects of lower doses of conventional antipsychotic drugs. ${ }^{107}$ This was on acquisition cost grounds. The work was widely criticized at the time, and was not translated into UK Government guidance regarding the drug treatment of schizophrenia 2 years later. ${ }^{108}$ Even so, later work concurred that the use of higher than recommended doses of haloperidol in comparator trials had taken place, and had hampered the interpretation of the results. ${ }^{109}$

It continued to be argued that amisulpride and other atypical antipsychotic drugs did possess genuine advantages over conventional antipsychotic drugs, particularly regarding tolerability. ${ }^{110}$ Amisulpride was suggested as a singularly good option when the antipsychotic drug needed to be changed, owing to its efficacy for negative and affective symptoms and its lack of redundant affinities ${ }^{111}$ or owing to its predecessor's lack of efficacy and tolerability in general. ${ }^{112}$ Indeed, a study which examined a variety of patients whose treatment was switched to amisulpride reported that the change was not problematic. ${ }^{113}$ More recent work has demonstrated advantages for risperidone treated patients switched to amisulpride ${ }^{96}$ including better memory performance.

Despite these encouraging findings, a large naturalistic study of outpatients has reported that amisulpride treated patients were less likely to remain on their treatment than patients treated with olanzapine ${ }^{114}$ and this has been replicated. ${ }^{115}$ In contrast a study of patients switched to 
amisulpride from conventional treatment observed an almost doubling of compliance rates. ${ }^{116}$

Nevertheless, the claimed rapid onset of action of amisulpride has made it a good choice for first-line treatment; ${ }^{24,117}$ while its versatility in terms of positive, negative, affective and cognitive symptoms coupled with its tolerability suited it to chronic treatment as well;118,119 Furthermore, four meta-analyses have now concluded that amisulpride is globally superior to conventional treatment and placebo across symptom profiles; ${ }^{38,120-122}$

Other work has supported this, in long term studies of patients with mixed positive and negative symptoms. ${ }^{123}$ A subsequent prospective appraisal of the effects of amisulpride on five different symptom dimensions concluded that it was effective for all. ${ }^{124}$

Therefore, amisulpride has been recommended as appropriate in most clinical scenarios for the treatment of schizophrenia, ${ }^{125}$ not just at low doses for patients with predominantly negative symptoms. Amisulpride is well tolerated compared to both conventional and other atypical antipsychotic drugs. ${ }^{126}$ Higher dosage ranges may be used without difficulty ${ }^{127}$ particularly in more severely ill patients. ${ }^{128}$ Nevertheless, most symptom dimensions in the BPRS including depression/anxiety and anhedonia/ negative symptoms will respond within the dose range of 400 to $800 \mathrm{mg}^{129}$

In comparison with other individual atypical antipsychotic drugs, there is evidence of overall superiority of symptom relief compared to risperidone in chronic patients ${ }^{130}$ although a similar study found no differences. ${ }^{131}$ Amisulpride appears equivalent to olanzapine in acute patients ${ }^{132}$ and in stable patients on a variety of outcome measures. ${ }^{133}$

Of two recent reviews, one concluded that it was difficult to distinguish atypical antipsychotic drugs in terms of efficacy ${ }^{134}$ while the other concluded that there were significant differences in both efficacy and tolerability. ${ }^{135}$ Nevertheless, amisulpride may offer advantages over other atypical antipsychotic drugs in the treatment of negative and depressive symptoms, and tolerability advantages such as the avoidance of weight gain. ${ }^{136}$

Unfortunately, the findings of the CATIE (Clinical Antipsychotic Trials for Intervention Effectiveness) schizophrenia trial published over the last 2 or 3 years have cast considerable doubt on the validity of differences between atypical and conventional antipsychotic drugs, both on a group and individual basis. As a North American study, CATIE did not include amisulpride, but there is little obvious reason to suspect that the inclusion of amisulpride would have substantially altered the findings. CATIE randomized an ordinary clinical sample of 1460 outpatients eligible for a change in medication: time to discontinuation was the primary outcome variable in terms of efficacy. Patients commenced one of four atypical antipsychotic drugs or perphenazine, a conventional antipsychotic drug, for 18 months. The 'take home messages' of CATIE were firstly that the atypical drugs demonstrated no efficacy or tolerability advantages over perphenazine, and secondly that $75 \%$ of the patients had discontinued the medication to which they had been randomized by the end. Objections to the validity and interpretation of the results are possible, but perhaps represent no more than 'starting points for sharpening debate and focusing efforts better in the future' ${ }^{137}$ in other words, the findings do stand up to scrutiny. The CUtLASS study in the UK, which implemented a broadly similar design, included amisulpride: CUtLASS reported similar findings to CATIE, and came to similar conclusions. ${ }^{138,139}$

The inevitable return to the argument that all antipsychotic drugs (except clozapine) are the same may be rebutted, nonetheless, by the contention that although this may be true for groups of patients, there is much inter-individual variability, particularly in the atypical group, in respect of side effects and possibly efficacy to some degree too. This is because what can be deduced from the high discontinuation rates in such trials as CATIE and CUtLASS is that no single medication suits all patients. In other words similarity of outcome applies to groups of patients, not to the individual patient: there remains the need for a high degree of skill and experience in choosing antipsychotic treatment for each person who needs it.

\section{Conclusions}

Amisulpride is an atypical antipsychotic drug with a unique mechanism of action. It differs from every other antipsychotic drug in that it is indicated for dysthymia: there is reasonably consistent evidence that amisulpride is useful in depressive symptoms and negative symptoms in schizophrenia, particularly at low doses. Amisulpride presents the best evidence for utility as an adjunct to clozapine in treatment resistant schizophrenia. These advantages compared to other antipsychotic drugs do not, however, preclude amisulpride from general use: it is effective in patients with positive symptoms, functional and cognitive compromise, in acute and long term clinical scenarios, first episode and relapse. Amisulpride is therefore a rational choice, both in general and in particular, for the treatment of patients with schizophrenia. 


\section{Disclosures}

The author declares no conflicts of interest.

\section{References}

1. Guo N, Guo W, Guillin O, Laruelle M, Javitch J, Rayport S. The surface D2-binding profile of the atypical antipsychotic drug amisulpride. J Cereb Blood Flow Metabo. 2007;27(suppl 1):PO03-02U.

2. Kerwin R. From pharmacological profiles to clinical outcomes. Int Clini Psychopharmacol. 2000;15(suppl 4):S1-S4.

3. Di Giovanni G, Di Mascio M, Di Matteo V, Esposito E. Effects of acute and repeated administration of amisulpride, a dopamine D2 D3 receptor antagonist, on the electrical activity of midbrain dopaminergic neurons. J Pharmacol Exp Ther. 1998;287(1):51-57.

4. Perrault G, Depoortere R, Morel E, Sanger D, Scatton B. Psychopharmacological profile of amisulpride: An antipsychotic drug with presynaptic D2 D3 dopamine receptor antagonist activity and limbic selectivity. J Pharmacol Exp Ther. 1997;280(1):73-82.

5. Navarro J, Manzaneque J, Vera F, Martin-Lopez M, Santin L. Amisulpride, a presynaptic D2 D3, dopamine receptor antagonist, induces catalepsy in mice. Med Sci Res. 1997;25(8):551-552.

6. Martinot J, Paillere-Martinot M, Poirier M, Dao-Castellana M, Loc'h C, Maziere B. In vivo characteristics of dopamine D2 receptor occupancy by amisulpride in schizophrenia. Source Psychopharmacol. 1996;124(1-2):154-158.

7. Xiberas X, Martinot J-L, Mallet L, et al. In vivo extrastriatal and striatal D2 dopamine receptor blockade by amisulpride in schizophrenia. J Clini Psychopharmacol. 2001;21(2):207-214.

8. Stone J, Bressan R, Erlandsson K, Ell P, Pilowsky L. Non-uniform blockade of intrastriatal D2 D3 receptors by risperidone and amisulpride. Psychopharmacol. 2005;180(4):664-669.

9. La Fougere C, Meisenzahl E, Schmitt G, et al. D2 receptor occupancy during high- and low-dose therapy with the atypical antipsychotic amisulpride: A 123 I-iodobenzamide SPECT study. J Nucl Med. 2005;46(6):1028-1033.

10. Perrault G, Schoemaker H, Scatton B. Amisulpride, an atypical neuroleptic. Encephale. 1996;22(spec. iss. 2):3-8.

11. Gessa G. Dysthymia and depressive disorders: Dopamine hypothesis. Eur Psychiatry. 1996;11(suppl 3):123s-127s.

12. Moller H-J. Amisulpride: Limbic specificity and the mechanism of antipsychotic atypicality. Prog Neuropsychopharmacol Biol Psychiatry. 2003;27(7):1101-1111.

13. Hamon-Vilcot B, Chaufour S, Deschamps C, et al. Safety and pharmacokinetics of a single oral dose of amisulpride in healthy elderly volunteers. Eur J Clini Pharmacol. 1998;54(5):405-409.

14. Puech A, Fleurot O, Rein W. misulpride, an atypical antipsychotic, in the treatment of acute episodes of schizophrenia: A dose-ranging study vs haloperidol. Acta Psychiatr Scand. 1998;98(1):65-72.

15. Grunder G, Wetzel H, Schlosser R, et al. Neuroendocrine response to antipsychotics: Effects of drug type and gender. Biol Psychiatry. 1999;45(1):89-97.

16. Lambert M, Haro J, Novick D, et al. Olanzapine vs. other antipsychotics in actual out-patient settings: Six months tolerability results from the European Schizophrenia Out-patient Health Outcomes study. Acta Psychiatr Scand. 2005;111(3):232-243.

17. Caccia S. Biotransformation of post-clozapine antipsychotics. Pharmacological implications. Clini Pharmacokinet. 2000;38(5):393-414.

18. Moller H-J. Amisulpride: A review of its efficacy in schizophrenia. Acta Psychiatr Scand Suppl. 2000;101(400):17-22.

19. Laux G. Amisulpride for treatment in schizophrenia with positive symptoms. Psychopharmakotherapie. 2000;7(3):106-110.

20. Burns T, Bale R. Clinical advantages of amisulpride in the treatment of acute schizophrenia. J Int Med Res. 2001;29(6):451-466.

21. Coukell A, Spencer C, Benfield P. Amisulpride. A review of its pharmacodynamic and pharmacokinetic properties and therapeutic efficacy in the management of schizophrenia. CNS Drugs. 1996;6(3):237-256.
22. Wetzel H, Grunder G, Hillert A, et al. Amisulpride versus flupentixol in schizophrenia with predominantly positive symptomatology A double-blind controlled study comparing a selective D2-like antagonist to a mixed D1 D2-like antagonist. Psychopharmacol. 1998; 137(3):223-232.

23. Freeman H. Amisulpride compared with standard neuroleptics in acute exacerbations of schizophrenia: Three efficacy studies. Int Clini Psychopharmacol. 1997;12(suppl 2):S11-S17.

24. Azorin J. Acute phase of schizophrenia: Impact of atypical antipsychotics. Int Clini Psychopharmacol. 2000;15(suppl 4):S5-S9.

25. Leucht S, Busch R, Hamann J, Kissling W, Kane J. Early-onset hypothesis of antipsychotic drug action: A hypothesis tested, confirmed and extended. Biol Psychiatry. 2005;57(12):1543-1549.

26. Bertolin Guillen J, Piles De La Fuente P, Vila Navarro C. Amisulpride in delusional disorders. An observational study. Arch Psiquiatria. 2005;68(4):301-308.

27. Scatton B, Claustre Y, Cudennec A, et al. Amisulpride: From animal pharmacology to therapeutic action. Int Clini Psychopharmacol. 1997;12(suppl 2):S29-S36.

28. Cudennec A, Fage D, Benavides J, et al. Effects of amisulpride, an atypical antipsychotic which blocks preferentially presynaptic dopamine autoreceptors, on integrated functional cerebral activity in the rat. Brain Res. 1997;768:257-265.

29. Danion J, Rein W, Fleurot O. Improvement of schizophrenic patients with primary negative symptoms treated with amisulpride. Am $J$ Psychiatry. 1999;156:610-616.

30. Moller H, Van Praag H, Aufdembrinke B, et al. Negative symptoms in schizophrenia: considerations for clinical trials. Psychopharmacol. 1994;115:221-228.

31. Loo H, Poirier-Littre M, Theron M, et al. Amisulpride versus placebo in the medium-term treatment of the negative symptoms of schizophrenia. Br J Psychiatry. 1997;170:18-22.

32. Boyer P, Lecrubier Y, Peuch A, et al. Treatment negative symptoms in schizophrenia with amisulpride. Br J Psychiatry. 1995;166:68-72.

33. Rein W, Turjanski S. Clinical update on amisulpride in deficit schizophrenia. Int Clini Psychopharmacol. 1997;12(suppl 2):S19-S27.

34. Moller H, Boyer P, Fleurot O, Rein W. Improvement of acute exacerbations of schizophrenia with amisulpride: A comparison with haloperidol. Psychopharmacol. 1997;132(4):396-401.

35. Peuskens J, Bech P, Moller H-J, Bale R, Fleurot O, Rein W. Amisulpride vs risperidone in the treatment of acute exacerbations of schizophrenia. Psychiatry Res. 1999;88(2):107-117.

36. Speller J, Barnes T, Curson D, Pantelis C, Alberts J. One-year, low-dose neuroleptic study of in-patients with chronic schizophrenia characterised by persistent negative symptoms. Amisulpride v. haloperidol. $\mathrm{Br} J$ Psychiatry. 1997;171:564-568.

37. Colonna L, Saleem P, Dondey-Nouvel L, Rein W. Long-term safety and efficacy of amisulpride in subchronic or chronic schizophrenia. Int Clini Psychopharmacol. 2000;15(1):13-22.

38. Leucht S. Amisulpride - A selective dopamine antagonist and atypical antipsychotic: Results of a meta-analysis of randomized controlled trials. Int J Neuropsychopharmacol. 2004;7(suppl 1):S15-S20.

39. Vaiva G, Thomas P, Llorca P, et al. SPECT imaging, clinical features, and cognition before and after low doses of amisulpride in schizophrenic patients with the deficit syndrome. Psychiatry Res. 2002;115(1-2): $37-48$.

40. Storosum J, Elferink A, Van Zwieten B, Van Strik R, Hoogendijk W, Broekmans A. Amisulpride: Is there a treatment for negative symptoms in schizophrenia patients? Schizophr Bull. 2002;28(2):193-201.

41. Olie J-P, Spina E, Murray S, Yang R. Ziprasidone and amisulpride effectively treat negative symptoms of schizophrenia: Results of a 12-week, double-blind study. Int Clini Psychopharmacol. 2006;21(3):143-151.

42. Lecrubier Y, Quintin P, Bouhassira M, Perrin E, Lancrenon S. The treatment of negative symptoms and deficit states of chronic schizophrenia: Olanzapine compared to amisulpride and placebo in a 6-month double-blind controlled clinical trial. Acta Psychiatrica Scand. 2006;114(5):319-327. 
43. Chiaie R, Caliari P. Chronic mild depressive symptoms: Rational use of amisulpride. Rivista di Psichiatria. 1997;32(suppl 6):77-93.

44. Pani L, Gessa G. The role of dopamine in the biological basis of dysthymia. Ital J Psychiatr Behav Sci. 1998;8(1):5-9.

45. Papp M, Wieronska J. Antidepressant-like activity of amisulpride in two animal models of depression. J Psychopharmacol. 2000;14(1):46-52.

46. Boyer P, Lecrubier Y. Atypical antipsychotic drugs in dysthymia: Placebo controlled studies of amisulpride versus imipramine, versus amineptine. Eur Psychiatry. 1996;11(suppl 3):135s-140s.

47. Smeraldi E, Haefele E, Crespi G, Casadei G, Biondi F, Vigorelli E. Amisulpride versus fluoxetine in dysthymia: Preliminary results of a double-blind comparative study. Eur Psychiatry. 1996;11(suppl 3): $141 \mathrm{~s}-143 \mathrm{~s}$.

48. Paes De Sousa M. Amisulpride in dysthymia: Results of a naturalistic study in general practice. Eur Psychiatry. 1996;11(suppl 3): $145 \mathrm{~s}-147 \mathrm{~s}$

49. Bogetto F, Barzega G, Bellino S, Maina G, Ravizza L. Drug treatment of dysthymia: A clinical study. Rivista di Psichiatria. 1997;32(1):1-5.

50. Boyer P, Lecrubier Y, Stalla-Bourdillon A, Fleurot O. Amisulpride versus amineptine and placebo for the treatment of dysthymia. Neuropsychobiol. 1999;39(1):25-32.

51. Ravizza L. Amisulpride in medium-term treatment of dysthymia: A six-month, double-blind safety study versus amitriptyline. J Psychopharmacol. 1999;13(3):248-254.

52. Rocca P, Fonzo V, Ravizza L, et al. A comparison of paroxetine and amisulpride in the treatment of dysthymic disorder. J Affect Disord. 2002;70(3):313-317.

53. Montgomery S. Dopaminergic deficit and the role of amisulpride in the treatment of mood disorders. Int Clini Psychopharmacol. 2002; 17(suppl 4):S9-S19.

54. Ceskova E. Deniban in the treatment of dysthymia. Ceska Slove Psychiatr. 2007;103(2):73-79.

55. Zanardi R, Smeraldi E. A double-blind, randomised, controlled clinical trial of acetyl-1-carnitine vs. amisulpride in the treatment of dysthymia. Eur Neuropsychopharmacol. 2006;16(4):281-287.

56. Lecrubier Y, Boyer P, Turjanski S, Rein W. Amilsulpride versus imipramine and placebo in dysthymia and major depression. $J$ Affect Disord. 1997;43(2):95-103.

57. Amore M, Jori M. Faster response on amisulpride $50 \mathrm{mg}$ versus sertraline 50-100 mg in patients with dysthymia or double depression: A randomized, double-blind, parallel group study. Int Clini Psychopharmacol. 2001;16(6):317-324.

58. Cassano G, Jori M. Efficacy and safety of amisulpride $50 \mathrm{mg}$ versus paroxetine $20 \mathrm{mg}$ in major depression: A randomized, double-blind, parallel group study. Int Clini Psychopharmacol. 2002;17(1): 27-32.

59. Smeraldi E. Amisulpride versus fluoxetine in patients with dysthymia or major depression in partial remission. A double-blind, comparative study. J Affect Disord. 1998;48(1):47-56.

60. Canal M, Legangneux E, Van Lier J, Van Viet A, Coulouvrat C. Lack of effect of amisulpride on the pharmacokinetics and safety of lithium. Int J Neuropsychopharmacol. 2003;6(2):103-109.

61. Svestka J. New psychotropics: Amisulpride - Atypical compound in the group of 2nd generation antipsychotics. Psychiatrie. 2000;4(3): 191-200.

62. Peuskens J, Moller H, Puech A. Amisulpride improves depressive symptoms in acute exacerbations of schizophrenia: comparison with haloperidol and risperidone. Eur Neuropsychopharmacol. 2002;12(4):05-310.

63. Vanelle J-M, Douki S. A double-blind randomised comparative trial of amisulpride versus olanzapine for 2 months in the treatment of subjects with schizophrenia and comorbid depression. Eur Psychiatry. 2006;21(8):523-530.

64. Kim S-W, Shin L-S, Kim J-M, et al. Amisulpride versus risperidone in the treatment of depression in patients with schizophrenia: A randomized, open-label, controlled trial. Progr in Neuropsychopharmacol Biol Psychiatry. 2007;31(7):1504-1509.
65. Hafner H, Maurer K, Ruhmann S, et al. Early detection and secondary prevention of psychosis: Facts and visions. Eur Archi Psychiatry Clini Neurosci. 2004;254(2):117-128.

66. Bechdolf A, Ruhmann S, Wagner M, et al. Interventions in the initial prodromal states of psychosis in Germany: Concept and recruitment. Br J Psychiatry. 2005;187(suppl 48):s45-s48.

67. Ruhmann S, Bechdolf A, Kuhn K, et al. Acute effects of treatment for prodromal symptoms for people putatively in a late initial prodromal state of psychosis. Br J Psychiatry. 2007;191(suppl 51):s88-s95.

68. Murphy B, Stuart A, Wade D, Cotton S, McGorry P. Efficacy of amisulpride in treating primary negative symptoms in first-episode psychosis: A pilot study. Hum Psychopharmacol. 2006;21(8): 511-517.

69. Kahn R, Fleischhacker W, Boter H, et al. Effectiveness of antipsychotic drugs in first-episode schizophrenia and schizophreniform disorder: an open randomised clinical trial. Lancet. 2008; 371(96110858): 1097

70. Kontaxakis V, Havaki-Kontaxaki B, Ferentinos P, Paplos K, Soldatos C. Switching to amisulpride monotherapy for treatment-resistant schizophrenia. Eur Psychiatry. 2006;21(3):214-217.

71. Croissant B, Hermann D, Olbrich R. Saving potential of clozapine due to combination with amisulpride. Psychopharmakotherapie. 2001;8(3):128-130.

72. Kampf P, Agelink M, Mass R, John H, Schafer I, Naber D. Amisulpride in addition to clozapine: A retrospective study indicates improved efficacy and good tolerability. Ger J Psychiatry. 2003;6(3):64-68.

73. Zink M, Knopf U, Henn F, Thome J. Combination of Clozapine and Amisulpride in Treatment-Resistant Schizophrenia - Case Reports and Review of the Literature. Pharmacopsychiatry. 2004b;37(1): 26-31.

74. Cook B, Hoogenboom G. Combined use of amisulpride and clozapine for patients with treatment-resistant schizophrenia. Australas Psychiatry. 2004;12(1):74-76.

75. Munro J, Matthiasson P, Osborne S, et al. Amisulpride augmentation of clozapine: An open non-randomized study in patients with schizophrenia partially responsive to clozapine. Acta Psychiatr Scand. 2004;110(4):292-298.

76. Frick A, Kopitz J, Kress K, Bergemann N. Clozapine raises plasma levels of amisulpride. Psychopharmakotherapie. 2003;10(1):28-31.

77. Zink M, Henn F, Thome J. Combination of amisulpride and olanzapine in treatment-resistant schizophrenic psychoses. Eur Psychiatry. 2004a;19(1):56-58.

78. Chan J, Sweeting M. Combination therapy with non-clozapine atypical antipsychotic medication: A review of current evidence. J Psychopharmacol. 2007;21(6):657-664.

79. Lerner V, Bergman J, Borokhov A, Loewenthal U, Miodownik C. Augmentation with amisulpride for schizophrenic patients nonresponsive to antipsychotic monotherapy. Clini Neuropharmacol. 2005; 28(2):66-71.

80. Zink M, Dressing H. Augmenting atypical antipsychotic medications with clozapin. Nervenarzt. 2005;76(9):1092-1102.

81. Ziegenbein M, Sieberer M, Kuenzel H, Kropp S. Augmentation of Clozapine with amisulpride in patients with treatment-resistant schizophrenia an open clinical study. Ger J Psychiatry. 2006;9(1): $17-22$.

82. Koen L, Niehaus D, Schulte A, Muller J, Emsley R, Oosthulzen P. Amisulpride as adjunct to clozapine in treatment-resistant schizophrenia and schizoaffective disorder: An open-label pilot study. Afr J Psychiatry (Johannesbg). 2006;12(1):17-20.

83. Assion H-J, Reinbold H, Lemanski S, Basilowski M, Juckel G. Amisulpride augmentation in patients with schizophrenia partially responsive or unresponsive to clozapine. A randomized, double-blind, placebocontrolled trial. Pharmacopsychiatry. 2008;41(1):24-28.

84. Genc Y, Taner E, Candansayar S. Comparison of clozapine-amisulpride and clozapine-quetiapine combinations for patients with schizophrenia who are partially responsive to clozapine: A single-blind randomized study. Adv Ther. 2007;24(1):1-13. 
85. Kreinin A, Novitski D, Weizman A. Amisulpride treatment of clozapine-induced hypersalivation in schizophrenia patients: A randomized, double-blind, placebo-controlled cross-over study. Int Clini Psychopharmacol. 2006;21(2):99-103.

86. Sockalingam S, Shammi C, Remington G. Clozapine-induced hypersalivation: A review of treatment strategies. Can J Psychiatry. 2007;52(6):377-384.

87. Mattila M, Patat A, Seppala T, et al. Single oral doses of amisulpride do not enhance the effects of alcohol on the performance and memory of healthy subjects. Eur J Clin Pharmacol. 1996;51(2):161-166.

88. Patat A, Rosenzweig P, Miget N, Allain H, Gandon J-M. Effects of $50 \mathrm{mg}$ amisulpride on EEG, psychomotor and cognitive functions in healthy sleep-deprived subjects. Fund Clini Pharmacol. 1999;13(5): 582-594.

89. Peretti C, Danion J, Kauffmann-Muller F, Grange D, Patat A, Rosenzweig P. Effects of haloperidol and amisulpride on motor and cognitive skill learning in healthy volunteers. Psychopharmacol. 1997;131(4):329-338.

90. Perault M, Bergougnan L, Paillat A, Zieleniuk I, Rosenzweig P, Vandel B. Lack of interaction between amisulpride and lorazepam on psychomotor performance and memory in healthy volunteers. Hum Psychopharmacol. 1998;13(7):493-500.

91. Ramaekers J, Louwerens J, Muntjewerff N, et al. Psychomotor, cognitive, extrapyramidal, and affective functions of healthy volunteers during treatment with an atypical (amisulpride) and a classic (haloperidol) antipsychotic. J Clini Psychopharmacol. 1999;19(3): 209-221.

92. Legangneux E, McEwen J, Wesnes K, et al. The acute effects of amisulpride (50 $\mathrm{mg}$ and $200 \mathrm{mg}$ ) and haloperidol $(2 \mathrm{mg})$ on cognitive function in healthy elderly volunteers. J Psychopharmacol. 2000;14(2):164-171.

93. Rosenzweig P, Canal M, Patat A, Bergougnan L, Zieleniuk I, Bianchetti G. A review of the pharmacokinetics, tolerability and pharmacodynamics of amisulpride in healthy volunteers. Hum Psychopharmacol. 2002;17(1):1-13.

94. Gibbs A, Naudts K, Spencer E, David A. The role of dopamine in attentional and memory biases for emotional information. Am J Psychiatry. 2007;164(10):1601-6093.

95. Morrens M, Hulstijn W, Sabbe B. The effects of atypical and conventional antipsychotics on reduced processing speed and psychomotor slowing in schizophrenia: A cross-sectional exploratory study. Clini Ther. 2008;30(4):684-692.

96. Wang Y-T, Chiu N-Y, Jou S-H, et al. Effects of amisulpride on the cognitive function of patients with schizophrenia who switched from risperidone. Int J Psychiatry Clini Pract. 2008;12(3):180-186.

97. Tyson P, Roberts K, Mortimer A. Are the cognitive effects of atypical antipsychotics influenced by their affinity to 5HT-2A receptors? Int J Neurosci. 2004;114(6);593-611.

98. Wagner M, Quednow B, Westeide J, Schlaepfer T, Maier W, Kuhn K-U. Cognitive improvement in schizophrenic patients does not require a serotonergic mechanism: Randomized controlled trial of olanzapine vs amisulpride. Neuropsychopharmacol. 2005;30(2): 381-390.

99. Mortimer A, Joyce E, Balasubramaniam D, Choudhary P, Saleem P. Treatment with amisulpride and olanzapine improve neuropsychological function in schizophrenia. Hum Psychopharmacol. 2007;22(7): $445-454$.

100. Chabannes J, Pelissolo A, Farah S, Gerrard D. Treatment of psychosis with productive symptoms: Efficacy and safety of amisulpride. Encephale. 1998;24(4):386-392.

101. Carriere P, Bonhomme D, Lemperiere T. Amisulpride has a superior benefit/risk profile to haloperidol in schizophrenia: Results of a multicentre, double-blind study (the amisulpride study group). Eur Psychiatry. 2000;15(5):321-329.

102. Saleem P, Olie J, Loo H. Social functioning and quality of life in the schizophrenic patient: Advantages of amisulpride. Int Clini Psychopharmacol. 2002;17(1):1-8.
103. Surguladze S, Patel A, Kerwin R, Knapp M, Travis M. Cost analysis of treating schizophrenia with amisulpride: Naturalistic mirror image study. Prog in Neuropsychopharmacol Biol Psychiatry. 2005;29(4):517-522.

104. Tyson P, Laws K, Flowers K, Tyson A, Mortimer A. Cognitive function and social abilities in patients with schizophrenia: Relationship with atypical antipsychotics. Psychiatry Clini Neurosci. 2006;60(4): 473-479.

105. Lambert M, Naber D, Eich F, Schacht M, Linden M, Schimmelmann B. Remission of severely impaired subjective wellbeing in 727 patients with schizophrenia treated with amisulpride. Acta Psychiatri Scand. 2007;1110625(113).

106. Falkai P, Vogeley K. Chances of new atypical substances. Fortschr Neurol Psychiatr. 2000;68(suppl 1):S32-S37.

107. Geddes J, Freemantle N, Harrison P, Bebbington P. Atypical antipsychotics in the treatment of schizophrenia: Systematic overview and meta-regression analysis. BMJ. 2000;321(7273):1371-1376.

108. Barnett D. Guidance on the use of newer (atypical) antipsychotic drugs for the treatment of schizophrenia. National Institute for Clinical Excellence. London. 2002;43.

109. Hugenholtz G, Heerdink E, Stolker J, Meijer W, Egberts A, Nolen W. Haloperidol dose when used as active comparator in randomized controlled trials with atypical antipsychotics in schizophrenia: Comparison with officially recommended doses. Source J Clin Psychiatry. 2006;67(6):897-903.

110. Ceskova E. Amisulpride-A new benzamide antipsychotic of the second generation. Ceska a Slovenska Psychiatrie. 2000;96(8):411-415.

111. Peuskens J. Switching approach in the management of schizophrenia patients. Int Clini Psychopharmacol. 2000;15(suppl 4):S15-S19.

112. Pani L, Villagran J, Kontaxakis V, Alptekin K. Practical issues with amisulpride in the management of patients with schizophrenia. Clini Drug Investig. 2008;28(8):465-477.

113. Burns T, Chabannes J, Demyttenaere K. Switching antipsychotic medications: General recommendations and switching to amisulpride. Curr Med Res Opin. 2002;18(4):201-208.

114. Haro J, Novick D, Belger M, Jones P. Antipsychotic type and correlates of antipsychotic treatment discontinuation in the outpatient treatment of schizophrenia. Eur Psychiatry. 2006;21(1):41-47.

115. Kahn R, Fleischhaker W, Boter H, et al. Effectiveness of antipsychotic drugs in first-episode schizophrenia and schizophreniform disorder: an open randomised clinical trial. Lancet. 2008;371(9618):1085-1097.

116. Linden M, Scheel T, Eich F-X. Improvement of patient compliance after switching from conventional neuroleptics to the atypical neuroleptic amisulpride. J Psychopharmacol. 2006;20(6):815-823.

117. Nuss P, Hummer M, Tessier C. The use of amisulpride in the treatment of acute psychosis. Ther Clini Risk Manage. 2007;3(1):3-11.

118. Lecrubier Y. Is amisulpride an 'atypical' atypical antipsychotic agent? Int Clin Psychopharmacol. 2000;15(suppl 4):S21-S26.

119. Curran M, Perry C. Amisulpride: A review of its use in the management of schizophrenia. Drugs. 2001;61(14):2123-2150.

120. Leucht S, Pitschel-Walz G, Engel R, Kissling W. Amisulpride, an unusual "atypical" antipsychotic: A meta-analysis of randomized controlled trials. Am J Psychiatry. 2002;159(2):180-190.

121. Davis J, Chen N, Glick I. A meta-analysis of the efficacy of secondgeneration antipsychotics. Arch Gen Psychiatry. 2003;60(6): 553-564.

122. Leucht S, Corves C, Arbter D, Engel R, Li C, Davis J. Second-generation versus first-generation antipsychotic drugs for schizophrenia: a metaanalysis. Lancet. 2009;373(9657):31-41.

123. Naber D, Arlt J, Lambert M. Amisulpride: A safe and effective option for the long-term treatment of patients with schizophrenia. Int $J$ Psychiatry Clini Pract. 2003;7(3):167-175.

124. Herrera-Estrella M, Apiquian R, Fresan A, Sanchez-Torres I.Institution. The effects of amisulpride on five dimensions of psychopathology in patients with schizophrenia: A prospective open-label study. $B M C$ Psychiatry. 2005;5(22).

125. McKeage K, Plosker G. Amisulpride: A review of its use in the management of schizophrenia. CNS Drugs. 2004;18(13):933-956. 
126. Rein W, Coulouvrat C, Dondey-Nouvel L. Safety profile of amisulpride in short- and long-term use. Acta Psychiatr Scand. 2000; Suppl 101(400):23-27.

127. Curran M, Perry C. Spotlight on amisulpride in schizophrenia. CNS Drugs. 2002;16(3):207-211.

128. Linden M, Scheel T, Eich F. Dosage finding and outcome in the treatment of schizophrenic inpatients with amilsupride. Results of a drug utilization observation study. Hum Psychopharmacol. 2004;19(2):111-119.

129. Muller M, Wetzel H, Eich F-X, Rein W, Puech A, Benkert O. Doserelated effects of amisulpride on five dimensions of psychopathology in patients with acute exacerbation of schizophrenia. J Clini Psychopharmacol. 2002;22(6):554-560.

130. Sechter D, Peuskens J, Fleurot O, et al. Amisulpride vs. risperidone in chronic schizophrenia: Results of a 6-month double-blind study. Neuropsychopharmacol. 2002;27(6):1071-1081.

131. Hwang T, Lee S-M, Sun H-J, et al. Amisulpride versus risperidone in the treatment of schizophrenic patients: A double-blind pilot study in Taiwan. J Form Med Assoc. 2003;102(1):30-36.

132. Mortimer A. How do we choose between atypical antipsychotics? The advantages of amisulpride. Int J Neuropsychopharmacol. 2004; 7(suppl 1):S21-S25.

133. Hofer A, Rettenbacher M, Edlinger M, et al. Outcomes in schizophrenia outpatients treated with amisulpride or olanzapine. Pharmacopsychiatry. 2007;40(1):1-8.
134. Motlova L, Spaniel F, Hoschl C, Balon R. Are there any differences in the efficacy among second generation antipsychotics in the treatment of schizophrenia and related disorders? Ann Clini Psychiatry. 2007;19(2):133-143.

135. Vohora D. Atypical antipsychotic drugs: Current issues of safety and efficacy in the management of schizophrenia. Curr Opin Investig Drugs. 2007;8(7):531-538.

136. Mortimer A, Martin S, Loo H, Peuskens J. A double-blind, randomized comparative trial of amisulpride versus olanzapine for 6 months in the treatment of schizophrenia. Int Clini Psychopharmacol. 2004; 19(2):63-69.

137. Manschreck T, Boshes R. The CATIE Schizophrenia Trial: results, impact, controversy. Mol Psychiatry. 2007;245-258.

138. Lewis S, Lieberman J. CATIE and CUtLASS: Can we handle the truth? Br J Psychiatry. 2008;192(3):161-163.

139. Lewis S, Davies L, Jones P, et al. Randomised controlled trials of conventional antipsychotic versus new atypical drugs, and new atypical drugs versus clozapine, in people with schizophrenia responding poorly to, or intolerant of, current drug treatment. Health Technol Assess. 2006;10(17):1-94.
Neuropsychiatric Disease and Treatment

\section{Publish your work in this journal}

Neuropsychiatric Disease and Treatment is an international, peerreviewed journal of clinical therapeutics and pharmacology focusing on concise rapid reporting of clinical or pre-clinical studies on a range of neuropsychiatric and neurological disorders. This journal is indexed on PubMed Central, the 'PsycINFO' database and CAS, and is the official

\section{Dovepress}

journal of The International Neuropsychiatric Association (INA). The manuscript management system is completely online and includes a very quick and fair peer-review system, which is all easy to use. Visit http://www.dovepress.com/testimonials.php to read real quotes from published authors. 